\title{
ATIVIDADE ANTIBIOFILME DE DITERPENO ISOLADO DE Croton antisyphiliticus FRENTE Staphylococcus aureus
}

\author{
ANTIBIOFILM ACTIVITY OF DITERPENO ISOLATED FROM Croton antisyphiliticus \\ AGAINST Staphylococcus aureus
}

\author{
T. T. NADER ${ }^{1}$, J. S. COPPEDE ${ }^{2}$, L. A. AMARAL ${ }^{3}$, A. M. S. PEREIRA ${ }^{4}$
}

\begin{abstract}
RESUMO
O presente estudo teve como principal objetivo avaliar o potencial de atividade antimicrobiana de diterpeno isolado de Croton antisyphiliticus, espécie nativa do Cerrado, frente biofilme de Staphylococcus aureus, isolados do leite de animais com mastite. O diterpeno ácido ent-kaur-16-en-18-óico foi avaliado quanto à capacidade de erradicação da biomassa e também à redução da população bacteriana sob o biofilme. O antibiótico sulfato de gentamicina foi utilizado como tratamento comparativo. A atividade antibiofilme foi determinada por meio dos métodos do Cristal Violeta e da Contagem de Unidades Formadoras de Colônia. Os resultados obtidos demonstraram que o ácido ent-kaur-16-en-18óico, na concentração de $250 \mu \mathrm{g} / \mathrm{mL}$, reduziu $56 \%$ da biomassa formada, enquanto a gentamicina, na concentração de $30 \mathrm{mg} / \mathrm{mL}$, apenas $13 \%$. Quanto à atividade nas células bacterianas sob o biofilme, não houve diferença estatística significativa entre os tratamentos, que minimizaram cerca de $3 \log$ s da população de $S$. aureus. Portanto, nas condições ensaiadas, o diterpeno ent-kaur-16-en-18-óico destacou-se por apresentar atividade antibiofilme significativa contra $S$. aureus, em concentração 120 vezes menor quando comparado ao antibiótico gentamicina.
\end{abstract}

PALAVRAS-CHAVE: Ácido ent-kaurenoic. Atividade antimicrobiana. Biofilme. Mastite. Croton

\section{SUMMARY}

The present study aimed to evaluate the potential antimicrobial activity of diterpene isolated from Croton antisyphiliticus, native species of the Cerrado, against biofilm of Staphylococcus aureus isolated from milk from animals with mastitis. The diterpene ent-Kaur-16-on-18-oic acid were evaluated for their ability to eradicate biomass and also reducing the bacterial population in the biofilm. The antibiotic gentamicin was used as a comparative treatment. Antibiofilm activity was determined by the methods of Crystal Violet and Count of Colony Forming Units. The results demonstrated that the ent-Kaur-16-on-18-oic acid, at a concentration of $250 \mu \mathrm{g} / \mathrm{mL}$, reduced $56 \%$ of the biomass formed, while gentamicin, at a concentration of $30 \mathrm{mg} / \mathrm{ml}$, only $13 \%$. Regarding the activity in bacterial cells in the biofilm, there was no statistically significant difference between treatments, that minimized about 3 logs of the population of S.aureus. Therefore, in the conditions tested, the diterpene ent-kaur-16-on-18-oic highlighted for presenting antibiofilm significant activity against $S$. aureus, at a concentration 120 times lower when compared to the gentamicin antibiotic.

KEY-WORDS: Antimicrobial activity. Biofilm. Ent-kaurenoic acid. Mastits. Croton

\footnotetext{
${ }^{1}$ Doutora em Medicina Veterinária Preventiva na Universidade Estadual Paulista "Júlio de Mesquita Filho" (Unesp), Campus de Jaboticabal - Jaboticabal/SP e Responsável Técnica pelo Laboratório de Experimentação Animal da Universidade de Ribeirão Preto (UNAERP) - Ribeirão Preto/SP. talitanader@hotmail.com

${ }^{2}$ Pós doutoranda do Departamento de Biotecnologia e Plantas Medicinais da Universidade de Ribeirão Preto (UNAERP) - Ribeirão Preto/SP

${ }^{3}$ Docente do Departamento de Medicina Veterinária Preventiva e Reprodução Animal da Universidade Estadual Paulista "Júlio de Mesquita Filho" (Unesp), Campus de Jaboticabal - Jaboticabal/SP

${ }^{4}$ Docente do Departamento de Biotecnologia e Plantas Medicinais da Universidade de Ribeirão Preto (UNAERP) - Ribeirão Preto/SP
} 


\section{INTRODUÇÃO}

A utilização de plantas com fins medicinais é uma das mais antigas formas de prática medicinal da humanidade, porém o uso de fitoterápicos com finalidade terapêutica foi oficialmente reconhecido pela Organização Mundial da Saúde em 1978. Estimase que $80 \%$ da população do planeta utilizam de algum modo, plantas medicinais como medicamentos (GARCIA, 1995).

Estudo estima que $50 \%$ dos fármacos empregados para o tratamento de infecções são de origem natural ou semissintética, e foram protótipos para 19,4\% dos medicamentos sintéticos (PRETTO, 2005).

A capacidade terapêutica dos compostos vegetais é atribuída à síntese de substâncias químicas que participam dos mecanismos de defesa da planta, denominadas metabólitos secundários. Há diversos fatores que podem influenciar na produção dessas substâncias e como consequência, na ação terapêutica da planta, tais como sazonalidade, temperatura, disponibilidade hídrica, ciclo circadiano, radiação ultravioleta, altitude, disponibilidade de nutrientes, exposição a patógenos, interações e adaptações coevolutivas do ecossistema envolvido, dentre outros (GOBBO-NETO \& LOPES, 2007).

$\mathrm{Na}$ Medicina Veterinária, também há a utilização de plantas medicinais ou de substâncias ativas. Em comunidades rurais o emprego de plantas medicinais para tratamento de animais, sempre se fez presente. De acordo com Silva et al (2013), das 52 famílias de um assentamento rural no Estado do Rio de Janeiro, $63,5 \%$ tratam seus animais com plantas medicinais. Em um questionário aplicado aos discentes de medicina veterinária do Estado do Rio Grande do Norte, $73,9 \%$ conheciam a fitoterapia, dos quais 36,2 $\%$ usaram-na e obtiveram resultados eficazes (ALMEIDA et al., 2006). Profissionais adeptos à fitoterapia também revelam alta frequência de sucessos em tratamento de parasitoses e enfermidades infecciosas, inclusive em tratamentos de mastite bovina (COSTA, 1998).

A mastite, processo inflamatório da glândula mamária, é classificada de acordo com a forma de apresentação, podendo ser clínica ou subclínica, e caracterizada como uma enfermidade de difícil controle e com grande impacto econômico e epidemiológico (IDF, 1987; BRAMLEY et al., 1996). Staphylococcus aureus destaca-se como o principal agente etiológico da mastite contagiosa e importante micro-organismo na epidemiologia de doenças veiculadas por alimentos, devido a sua alta prevalência e produção de toxinas termorresistentes causadoras de intoxicações alimentares no ser humano (SILVA et al., 2010; MELLO et al., 2012).

O tratamento convencionalmente realizado por antibioticoterapia, quando utilizado de forma indiscriminada e inadequada, proporciona resistência bacteriana a diversos princípios ativos e acarreta sérios prejuízos ao consumidor, à indústria e ao rebanho, devido ao risco da presença de resíduos de antibióticos no produto final (BRANCO et al., 2012; VIEIRA et al., 2012).

Mitidiero (2012) avaliou os aspectos sanitários e de produção de uma bovinocultura leiteira na qual os animais eram tratados apenas com homeopatia, bioterápicos e fitoterapia e concluiu que em relação à mastite, é viável realizar o controle sanitário em um rebanho leiteiro de alta produção pelo uso destas terapêuticas em substituição aos medicamentos alopáticos, com redução nos custos de produção, sem comprometer o desempenho produtivo e sem os riscos da contaminação do leite por resíduos. Schuch (2008) avaliou a atividade antisséptica e desinfetante de extratos vegetais e decoctos das espécies Baccharis trimera, Bidens pilosa, Eucalyptus sp, Polygonum hidropiper e Tagetes minuta frente Staphylococcus coagulase positiva, Staphylococcus coagulase negativa, Streptococcus spp., e Pseudomonas aeruginosas, causadores de mastite bovina e concluiu que os extratos vegetais apresentaram atividade antibacteriana, com destaque para a espécie Eucalyptus sp., que inativou todos os micro-organismos avaliados.

Staphylococcus aureus possui estirpes capazes de produzir biofilmes, que são constituídos por bactérias aderidas a qualquer superfície envolvidas por uma matriz de polímeros orgânicos, denominada biomassa, sob os quais os micro-organismos continuam a se multiplicar (COSTERTON et al., 1999). As células em biofilme apresentam características de desenvolvimento e traços fenotípicos únicos, quando comparados com as mesmas células presentes em culturas planctônicas (livres), tornando-as 10 a 1000 vezes mais resistentes a agentes antimicrobianos e fatores imunes do hospedeiro (ZANIN et al., 2006). Também são mais resistentes à ação de agentes físicos e químicos como os utilizados nos procedimentos de higienização (MARQUES, 2005). Portanto, as características do micro-organismo causador também interferem no sucesso terapêutico da mastite bovina.

Estudos observaram que extratos vegetais e substâncias isoladas apresentaram expressiva atividade inibitória sobre micro-organismos cultivados na forma livre e em biofilme quando comparado aos antibióticos convencionalmente utilizados (SAISING et al., 2011; COBRADO et al., 2012; LAPLANT et al., 2012).

Popularmente Croton antisyphiliticus Mart. é conhecido como pé-de-perdiz e suas folhas frescas são utilizadas no tratamento de lesões de pele, inflamações e como cicatrizante (RODRIGUES et al., 2002; FENNER et al., 2006). Esta espécie pertence ao gênero Croton, segundo maior gênero da família Euphorbiaceae, que possui cerca de 1.200 espécies e estão amplamente distribuídos em regiões de clima tropical (GOVAERTS et al. 2000).

Segundo Nader et al. (2010), o extrato clorofórmico de Croton antisyphiliticus, na concentração de $5 \mathrm{mg} / \mathrm{mL}$, apresentou destacada atividade bactericida in vitro, frente Staphylococcus aureus isolados de leite de animais com mastite, com resultados superiores aos obtidos com o antibiótico sulfato de gentamicina $(30 \mathrm{mg} / \mathrm{mL})$, utilizado no estudo. 
Um estudo fitoquímico do extrato clorofórmico da raíz de Croton antisyphiliticus realizado por Pereira et al. (2012), avaliou a atividade antimicrobiana e demonstrou que o ácido ent-kaur-16-en-18-óico foi isolado como componente majoritário com um valor de Concentração Inibitória Mínima (MIC) de $250 \mu \mathrm{g} / \mathrm{mL}$ contra S. aureus ATCC 6538 na forma livre. Em relação a isolados clínicos de $S$. aureus a MIC foi de 2 $\mathrm{mg} / \mathrm{mL}$. De acordo com a composição e estruturação molecular, esta substância foi considerada um epímero do ácido kaurenóico, ou seja, diferem no posicionamento do grupo hidroxila. A MIC do ácido kaurenóico, nas mesmas condições, $125 \mu \mathrm{g} / \mathrm{mL}$ e 2 $\mathrm{mg} / \mathrm{mL}$, respectivamente, para cepa ATCC e isolado clínico de $S$. aureus. Neste estudo, a gentamicina foi utilizada como controle negativo na MIC de 0,125 $\mu \mathrm{g} / \mathrm{mL}$.

Wilkens et al. (2002) constataram atividade bactericida do diterpeno natural ácido kaurenóico frente bactérias Gram positivas. Segundo Jeong et al. (2013), o ácido kaurenóico isolado a partir de Aralia continentalis atuou de maneira significativa sobre o biofilme de Streptococcus mutans, em concentrações de $4 \mu \mathrm{g} / \mathrm{mL}$.

Considerando a vasta diversidade vegetal com potencial terapêutico e estudos prévios com a espécie vegetal utilizada, conforme literatura apresentada, o presente estudo teve como objetivo investigar o potencial de atividade antimicrobiana in vitro do diterpeno ent-kaur-16-on-18-oic, isolado a partir de raíz de Croton antisyphiliticus, frente Staphylococcus aureus em biofilme.

\section{MATERIAL E MÉTODOS}

O diterpeno ácido ent-kaur-16-en-18-óico foi isolado a partir do extrato clorofórmico de raízes de Croton antisyphiliticus por Pereira et al. (2012), e cedido ao Departamento de Biotecnologia de Plantas Medicinais da Universidade de Ribeirão Preto (UNAERP). Esta substância foi avaliada na concentração de $250 \mu \mathrm{g} / \mathrm{mL}$.

Para efeito comparativo, o antibiótico sulfato de gentamicina (Sigma aldrich@) também foi avaliado neste estudo, na concentração de $30 \mathrm{mg} / \mathrm{mL}$, por ser esta, a apresentação comercial mais utilizada para o tratamento da mastite bovina (FONTANA et al., 2011).

Utilizou-se quatro estirpes de Staphylococcus aureus, isoladas de leite de animais com mastite e identificadas genotípica e fenotipicamente por Melo et al (2012) como produtoras de biofilme, e uma cepa padrão ATCC 25923.

Para a formação de biofilme in vitro as estirpes foram padronizadas em espectrofotômetro $\left(10^{5} \mathrm{UFC} / \mathrm{mL}\right)$ e incubadas em placas de 96 poços, em estufa bacteriológica a $37^{\circ} \mathrm{C}$, sob agitação (120 rpm). O meio de cultura utilizado foi o Brain Heart Infusion (BHI - Himedia ${ }^{\circledR}$ ) enriquecido com glicose $2 \%$. Após 24 horas de incubação, as placas foram lavadas duas vezes com $200 \mu \mathrm{L}$ de solução salina a $0,9 \%$, para remoção de células não aderidas (GOMES, 2010).

As células bacterianas que permaneceram aderidas ao poço receberam $100 \mu \mathrm{L}$ do meio de cultura
(BHI enriquecido com glicose 2\%) e $100 \mu \mathrm{L}$ das substâncias a serem avaliadas quanto ao potencial de erradicação do biofilme, ou seja, diterpeno ácido entkaur-16-en-18-óico $(250 \mu \mathrm{g} / \mathrm{mL})$ e gentamicina $(30 \mathrm{mg} / \mathrm{mL})$. As placas foram incubadas nas mesmas condições descritas anteriormente.

A atividade das substâncias sobre o biofilme de $S$. aureus foi avaliada por meio de dois métodos descritos na literatura, o Cristal Violeta (CV) e a Contagem de Unidades Formadoras de Colônia (UFC/mL), e todos os ensaios foram realizados em triplicata.

A técnica do Cristal Violeta, é um método colorimétrico que tem a propriedade de mensurar a quantidade de biomassa formada (matrix de polissacarídeos). Consistiu na lavagem dos poços para remoção das células não aderidas com solução salina, seguida da adição de $200 \mu \mathrm{L}$ de metanol para fixação das células aderidas (permanência por 5 minutos), adição de $200 \mu \mathrm{L}$ do cristal violeta (solução Violeta Cristal em meio aquoso Dinamica $\left.{ }^{\circledR}\right)$, lavagem com água destilada e uso de ácido acético a 33\% (200 $\mu \mathrm{L})$ para leitura de densidade óptica do biofilme (GOMES, 2010). O inóculo livre de tratamento foi utilizado como controle negativo.

A Contagem de Unidades Formadoras de Colônia permitiu quantificar as células que permaneceram viáveis sob o biofilme após os tratamentos. Nesta técnica, as placas também foram lavadas com solução salina, conforme descrito anteriormente, em seguida os poços foram raspados (utilizando ponteiras estéreis de $200 \mu \mathrm{L}$ ) e a placa foi submetida a um banho de ultrasom para promover desagregação das células aderidas, possibilitando a contagem. O tempo de exposição ao ultrasom que conferiu maior desagregação sem ocasionar morte celular neste experimento, foi padronizado em 8 minutos, na frequência de $40 \mathrm{~Hz}$ (Unique® Ultrasonic Cleaner). Para a contagem das colônias, o conteúdo dos poços foi diluído em doze vezes. Posteriormente, fezse o plaqueamento em meio de cultura Agar Brain Heart Infusion (Himedia ${ }^{\circledR}$ ) (em placas de Petri de 90 $\mathrm{mm})$ na forma de gotejamento (3 gotas $/ 10 \mu \mathrm{L}$ cada), incubou-se por 24 horas a $37^{\circ} \mathrm{C}$ (GOMES, 2010). Os valores obtidos foram transformados em escala logarítmica.

A análise estatística do experimento foi realizada pelo programa SISVAR, versão Sisvar 5.1 Build 72 (FERREIRA, 2011). O teste estatístico aplicado foi Scott Knott, com nível de significância de $5 \%(\alpha=0,05)$.

\section{RESULTADOS E DISCUSSÃO}

De acordo com a técnica do Cristal Violeta, o diterpeno ácido ent-kaur-16-en-18-óico, na concentração de $250 \mu \mathrm{g} / \mathrm{mL}$, erradicou $56 \%$ da biomassa, enquanto o sulfato de gentamicina, na concentração de $30 \mathrm{mg} / \mathrm{mL}$, erradicou $13,9 \%$ da matrix bacteriana. Portanto, a substância de origem vegetal em estudo, apresentou atividade microbiana sobre a biomassa de $S$. aureus significativamente superior ao antibiótico gentamicina $(\mathrm{p}<0,5)$ (Tabela 1). 
Tabela 1 - Médias de atividade antibiofilme do diterpeno ácido ent-kaur-16-en-18-óico, oriundo da raíz de Croton antisyphiliticus na concentração de $250 \mu \mathrm{g} / \mathrm{mL}$, frente Staphylococcus aureus, em comparação com sulfato de gentamicina, na concentração de $30 \mathrm{mg} / \mathrm{mL}$.

\begin{tabular}{|c|c|c|}
\hline Tratamentos & $\begin{array}{c}\text { Redução da biomassa } \\
(\text { matriz }) \\
\text { Cristal Violeta } \\
(\mathbf{C V})\end{array}$ & $\begin{array}{c}\text { Redução da população bacteriana } \\
\text { Contagem de Unidades Formadoras de } \\
\text { Colônia (UFC/mL) }\end{array}$ \\
\hline ácido ent-kaur-16-en-18-óico \\
$\mathbf{2 5 0 \mu g / \mathbf { m L }}$ & $56 \% \mathrm{a}^{*}$ & $3,12 \mathrm{a}^{* *}$ \\
\hline Gentamicina & $13,9 \% \mathrm{~b}^{*}$ & $3,14 \mathrm{a}^{* *}$ \\
\hline $\mathbf{3 0 m g / m L}$ & & $0 \mathrm{~b}^{* *}$ \\
\hline Controle & $0 \% \mathrm{c}^{*}$ & \\
\hline
\end{tabular}

Médias seguidas das mesmas letras não diferem estatisticamente entre si pelo teste Scott Knott $(\alpha=0,05)$. $*$ Letras correspondentes à análise estatística do método $\mathrm{CV}$, **Letras correspondentes à análise estatística do método UFC/mL.

No que diz respeito à quantificação das células bacterianas viáveis sob o biofilme, por meio da Contagem de Unidades Formadoras de Colônia, o diterpeno ácido ent-kaur-16-en-18-óico apresentou desempenho semelhante à gentamicina, reduzindo cerca de $3 \operatorname{logs}$ da população bacteriana $(p>0,05)$, porém em concentrações 120 vezes inferior (Tabela 1).

No presente estudo, a atividade antimicrobiana do diterpeno ácido ent-kaur-16-en-18-óico, oriundo do extrato clorofórmico de raíz de Croton antisyphiliticus na concentração de $250 \mu \mathrm{g} / \mathrm{mL}$, corroborou com os dados apresentados por Pereira et al. (2012), que observaram atividade antimicrobiana frente estirpes livres de $S$. aureus, nas mesmas concentrações. Bem como, concordou com Nader et al. (2010), que constatou que a atividade do extrato clorofórmico da raíz de Croton antisyphiliticus, frente ao mesmo microorganismo foi superior à atividade da gentamicina (30mg/mL). Segundo Wilkens et al. (2002), os diterpenos naturais possuem atividade bactericida sobre bactérias Gram positivas.

Em comparação ao ácido kaurenóico isolado a partir de Aralia continentalis, os valores de MIC obtidos neste estudo, divergem dos resultados apresentados por Jeong et al. (2013), que avaliou a atividade antibiofilme sobre o micro-organismo Streptococcus mutans. Tal fato deve-se às características dos micro-organismos presentes no biofilme e também às diferenças químicas estruturais entre as substâncias analisadas (ácido ent-kaur-16-en18-óico e ácido kaurenóico).

Pereira et al. (2012) demonstraram que a gentamicina inibiu a multiplicação de estirpes de $S$. aureus na concentração de $125 \mu \mathrm{g} / \mathrm{mL}$. No presente estudo, o mesmo antibiótico, na concentração de 30 $\mathrm{mg} / \mathrm{mL}$, não foi capaz de eliminar todos os microorganismos em biofilme. Esta diferença ocorreu em função da condição de multiplicação celular em biofilme, que dificulta consideravelmente a ação de qualquer substância, podendo tornar os microorganismos até 1000 vezes mais resistentes a agentes antimicrobianos, desinfetantes, sanitizantes e também a fatores imunes do hospedeiro (ZANIN et al., 2006; MARQUES, 2005).

\section{CONCLUSÃO}

Nas condições testadas, o diterpeno ácido ent-kaur-16en-18-óico, isolado a partir de extrato clorofórmico de raíz de Croton antisyphiliticus, destacou-se por apresentar atividade antibiofilme significativa contra Staphylococcus aureus, em concentração 120 vezes menor quando comparado ao antibiótico gentamicina. Assim, considerando os diversos aspectos relacionados ao tratamento da mastite bovina e à resistência bacteriana, como a presença de biofilmes, o diterpeno ácido ent-kaur-16-en-18-óico pode representar uma possibilidade terapêutica futura, embora estudos sejam necessários para conhecer os aspectos farmacológicos desta substância e identificar outros micro-organismos sensíveis.

\section{REFERÊNCIAS}

À Fundação de Apoio a Pesquisa do Estado de São Paulo (FAPESP) pelo financiamento do projeto e ao Conselho Nacional de Desenvolvimento e Pesquisa (CNPq) pela bolsa concedida durante a execução da pesquisa.

\section{REFERÊNCIAS}

ALMEIDA, K.S.; FREITAS, F.L.C.; PEREIRA, T.F.C. Etnoveterinária: a fitoterapia na visão do futuro profissional veterinário. Revista Verde, v.1, n.1, p.6774, 2006.

BRANCO, L. O.; DIAS, R.F.; LIMA-RIBEIRO, A.M.C. Bases de medicamentos para mastite mais vendidas na região de Uberlândia. Veterinária Notícias, v.18. n.2, p.26, 2012. 
BRAMLEY, A.J.; CULLOR, J.S.; ERSKINE, R.J.; FOX, L.K.; HARMON, R.J.; HIGAN, J.S.; NICKERSON, S.C.; OLIVER, S.P.; SMITH, K.L.; SORDILLO. Current concepts of bovine mastitis. 4 ed. Madison: The National Mastitis Council, 1996, $64 p$.

COBRADO, L.; AZEVEDO, M.M.; SILVA-DIAS, A.. Cerium, chitosan and hamamelitannin as novel biofilm inhibitors? Journal of Antimicrobial Chemotherapy, v.67, n.5, p.1159-1162, 2012.

COSTA, B. Homeopatia na cura e prevenção de doenças. Revista Balde Branco, n.405, p.28-33, 1998.

COSTERTON, J. W.; STEWART, P.S.; GREENBERG, E.P. Bacterial Biofilms: A common cause of persistent infections. Science, v.284, n.5418, p.1318-1322, 1999.

FENNER, R.; BETTI, A.H.; MENTZ, L.A.; RATES, S.M.K. Plantas utilizadas na medicina popular brasileira com potencial atividade antifúngica. Revista Brasileira de Ciências Farmacêuticas, v.42, n.3, p.369-394, 2006.

FERREIRA, D.F. Sisvar: a computer statistical analysis system. Ciência e Agrotecnologia (UFLA), v.35, n.6, p.1039-1042, 2011.

FONTANA, V.L.D.S.; GIANNINI, M.J.S.M.; LEITE, C.G.F.; MIRANDA, E.T.; ALMEIDA, A.M.F.; FONTANA, C.A.P.; SOUZA, C.M.; STELLA, A.E. Etiologia da mastite subclínica, sensibilidade dos agentes às drogas antimicrobianas e detecção do gene $\beta$-Lactamase em Staphylococcus aureus. Veterinária e Zootecnia, v.17, n.4, p.552-559, 2010.

GARCIA, E. S. Biodiversidade, biotecnologia e saúde. Cadernos de Saúde Pública, v.11, n.3, p.495-500, 1995.

GOBBO-NETO, L.; LOPES, P.N. Plantas medicinais: fatores de influência no conteúdo de metabólitos secundários. Química Nova, v.30, n.2, p.374-381, 2007.

GOMES, I.A.G. New therapeutic strategies against Staphylococcus epidermidis biofilms. Dissertation for $\mathrm{PhD}$ degree in Biomedical Engineering. Escola de Engenharia. Universidade do Minho. Portugal. 137p. 2010.

GOVAERTS, R.; FRODIN, D.G.; RADCLIFFESMITH, A. World Checklist and Bibliography of Euphorbiaceae (and Pandaceae), v.2, Royal Botanical Gardens, 2000.

JEONG, S.; et al. Kaurenoic Acid from Aralia continentalis Inhibits Biofilm Formation of Streptococcus mutans. Evidence-based Complementary and Alternative Medicine, 2013. Disponível em: <http://dx.doi.org/10.1155/2013/160592>. Acesso em: 08 agosto 2013.
INTERNATIONAL DAIRY FEDERATION. Bovine mastitis: definition and guidelines for diagnosis. Brussels, Belgium: International Dairy Federation: Bulletin 211, 1987. 24p.

LAPLANT, K.L.; SARKISIAN, S.A.; WOODMANSEE, S. Effects of Cranberry Extracts on Growth and Biofilm Production of Escherichia coli and Staphylococcus species. Phytotherapy Research, v.26, n.9, p.1371-1374, 2012.

MARQUES, C.S. Formação de Biofilmes por Staphylococcus aureus na superfície de aço inoxidável e vidro e sua resistência a sanificantes químicos. Dissertação (Mestrado em Ciência e Tecnologia de Alimentos), Universidade Federal de Lavras, Lavras - MG, 2005.

MELO, P.C.; FERREIRA, L.M.; NADER-FILHO, A.; ZAFALON, L.F.; VICENTE, H.I.G.. Análise fenotípica e molecular da produção de biofilmes por estirpes de Staphylococcus aureus isoladas de casos de mastite subclínica bovina. Bioscience, v.28, n.1, p.9499, 2012.

MELLO, P.F.; AGOSTINIS, R.O.; BARZON, E.M.; COLOMBO, R.B.; SILVA, A.V.; MARTINS, L.A. Prevalência da mastite subclínica e associação dos agentes etiológicos com a contagem de células somáticas de vacas leiteiras da região Sudoeste do Paraná. Veterinária e Zootecnia, v.19, n.4, p. 513521,2012

MITIDIERO, A.M.A. Potencial do uso de homeopatia, bioterápicos e fitoterapia como opção na bovinocultura leiteira. Dissertação (Mestrado) Universidade Federal de Santa Catarina, Centro de Ciências Agrárias. Programa de Pós-Graduação em Agroecossistemas. 132p. 2012.

NADER, T.T.; COPPEDE, J.S.; AMARAL, L.A.; FACCHIN, A.L.; PEREIRA, A.M.S.; FERREIRA, L.M. Avaliação in vitro da eficácia de extratos de plantas medicinais do Cerrado frente Staphylococcus aureus isolados de diferentes fontes de propriedades leiteiras. Arquivos do Instituto Biológico, v.77, n.3, p.429-433, 2010.

PEREIRA, S.; TALEB-CONTINI, S.; COPPEDE, J.; PEREIRA, P., BERTONI, B.; FRANÇA, S.; PEREIRA, A.M. An ent-Kaurane-Type Diterpene in Croton antisyphiliticus Mart. Molecules, 2012. Disponível em: <http://dx. doi: 10.3390/molecules17088851>. Acesso em: 30 julho 2013.

PRETTO, J.B. Potencial antimicrobiano de extratos, frações e compostos puros obtidos de algumas plantas da flora catarinense. Dissertação (Mestrado em Ciências Farmacêuticas), Universidade do Vale do Itajaí, Vale do Itajaí, 74p. 2005. 
RODRIGUES, L.A.; CARVALHO, D.A.; GOMES, L.J. Espécies vegetais nativas usadas pela população local em Luminárias - MG. Lavras: Boletim Agropecuário UFLA, n.52, 2002. 34p.

SAISING, J.; ONGSAKUL, M.; VORAVUTHIKUNCHAI, S.P. Rhodomyrtus tomentosa (Aiton) Hassk. Ethanol extract and rhodomyrtone: a potential strategy for the treatment of biofilm-forming staphylococci. Journal Medicine Microbiology, v.60, n.12, p.1793-1800, 2011.

SCHUCH, L.F.D. Plantas medicinais em atenção primária veterinária: atividade antimicrobiana frente a bactérias relacionadas com mastite bovina e a dermatófitos. Tese (Doutorado). Faculdade de Veterinária, Universidade Federal do Rio Grande do Sul, Programa de Pós Graduação em Ciências Veterinárias, Porto Alegre, 205p. 2008.

SILVA, E.P.; BERGAMINI, A.M.M.; OLIVEIRA. M.A. Toxinfecções alimentares na região de Ribeirão Preto, SP, Brasil - 2005 a 2008. Boletim Epidemiológico Paulista, v.7, n.77, p.4-10, 2010.
SILVA, W.M.O.D.; SOUZA, G.F.X.T.; VIEIRA, P.B.; SANAVRIA, A. Uso popular de plantas medicinais na promoção da saúde animal em assentamentos rurais de Seropédica - RJ. Revista Brasileira de Ciências Veterinárias, v. 20, n.1, p.32-36, 2013.

VIEIRA, T.S.W.J.; RIBEIRO, M.R.; NUNES, M.P.; MACHINSKI JUNIOR, M.; NETTO, D.P. Detecção de resíduos de antibióticos em amostras de leite pasteurizado do Estado do Paraná, Brasil. Ciências Agrárias, v.33, n.2, p.791-796, 2012.

WILKENS, M.; ALARCON, C.; URZUA, A.; MENDOZA, L. Characterization of the Bactericidal Activity of the Natural Diterpene Kaurenoic Acid. Planta Medica, v.68, n.5, p.452-454, 2002.

ZANIN, I.C.J.; LOBO, M.M.; RODRIGUES, L.K.A.; PIMENTA, L.A.F.; HOFLING, J.F.; GONÇALVES, R.B. Photosensitization of in vitro biofilms by toluidine blue $\mathrm{O}$ combined with light-emitting diode. European Journal of Oral Science, v.114, n.1, p.649, 2006. 